\title{
Effects of Long-Chain, Saturated Fatty Acids on Membrane Microviscosity and Adrenocorticotropin Responsiveness of Human Adrenocortical Cells In Vitro
}

\author{
Randall W. Whitcomb, * W. Marston Linehan, ${ }^{\star}$ and Richard A. Knazek* \\ *Developmental Endocrinology Branch, National Institute of Child Health and Human Development, National Institutes of Health, \\ Bethesda, Maryland 20982; and ${ }^{\ddagger}$ Surgery Branch, National Cancer Institute, National Institutes of Health, Bethesda, Maryland 20892
}

\begin{abstract}
Adrenoleukodystrophy (ALD) and adrenomyeloneuropathy are inherited disorders in which long-chain, saturated fatty acids (LCFA) accumulate in various tissues. A mechanism by which LCFA cause the endocrine and neurological dysfunction characteristic of these diseases is proposed based on in vitro response of human adrenocortical cells to ACTH in the presence of various fatty acids.

Human adrenocortical cells cultured in the presence of 5 $\mu \mathrm{M}$ hexacosanoic (C26:0) or lignoceric (C24:0) acids showed decreased basal and ACTH-stimulated cortisol release compared with cells cultured without exogenous fatty acids or in the presence of linoleic acid (C18:2). Measurement of fluorescence polarization demonstrates a significant increase in the membrane microviscosity of cells cultured in the presence of LCFA.

It is hypothesized that cells exposed to LCFA have increased membrane microviscosity with a consequent decrease in their ability to respond to ACTH. This decrease in trophic support may contribute to the adrenal insufficiency and atrophy in patients with ALD.
\end{abstract}

\section{Introduction}

Adrenoleukodystrophy (ALD) ${ }^{1}$ and adrenomyeloneuropathy are inherited disorders characterized by primary adrenal insufficiency, demyelination, and accumulation of long-chain, saturated fatty acids (LCFA), particularly hexacosanoic acid (C26:0), in the tissues of affected individuals (1-3). Both $x-$ linked and autosomal genotypes have been described $(4,5)$. The $x$-linked type may present in childhood, or as the adrenomyeloneuropathy variant with a more chronic onset, usually affecting young adults (6). Although the exact pathophysiologic mechanisms are not fully understood, the enzymatic defect in both genotypes appears to be in the peroxisomal $\beta$-oxidation system leading to abnormal metabolism of $\operatorname{LCFA}(7,8)$. The role that the accumulated LCFA play in the pathogenesis of the disease, particularly the adrenal insufficiency, is unknown.

We have previously reported an increase in the membrane microviscosity of erythrocytes obtained from ALD patients

Address all correspondence to Dr. R. W. Whitcomb, Bldg. 10, Rm. 10N262, National Institutes of Health, Bethesda, MD 20892.

Received for publication 5 June 1987 and in revised form 24 August 1987.

1. Abbreviations used in this paper: ALD, adrenoleukodystrophy; DPH, 1,6 diphenyl-hexatriene; LCFA, long-chain, saturated fatty acids; THF, tetrahydrofuran.

The Journal of Clinical Investigation, Inc.

Volume 81, January 1988, 185-188
(9). It has been suggested that the increased levels of hexacosanoic acid found in the adrenal glands of individuals with ALD might also result in an increase in the membrane microviscosity of these cells with subsequent alterations in ACTH activity, leading to the development of adrenal insufficiency (9). We now present evidence that both the membrane microviscosity as well as basal and ACTH-stimulated cortisol release are altered in human adrenocortical cells cultured in the presence of LCFA.

\section{Methods}

\section{Materials}

Materials were purchased from the following suppliers: Cortisol, dextran, gelatin, normal rabbit serum, tris buffer, linoleic acid, hexacosanoic acid, lignoceric acid, collagenase, deoxyribonuclease, and EDTA (Sigma Chemical Co., St. Louis, MO); 1,6 diphenylhexatriene (DPH) (Aldrich Chemical Co., Inc., Milwaukee, WI); tetrahydrofuran (THF) (Waters Associates, Milford, MA); charcoal and sucrose (Fisher Scientific Co., Pittsburgh, PA); and Ham's F-12 media, FCS, glutamine, penicillin, streptomycin, and PBS (Quality Biological, Inc., Gaithersburg, MD).

\section{Media and adrenocortical cell preparation}

FCS was incubated with charcoal $(0.75 \mathrm{~g} / 300 \mathrm{ml})$ for $60 \mathrm{~min}$ at $37^{\circ} \mathrm{C}$, centrifuged at $800 \mathrm{~g}$ for $10 \mathrm{~min}$, and filtered through a $0.2-\mu \mathrm{m}$ filter. The media used in all experiments was Ham's F-12 containing $10 \%$ charcoal-stripped FCS, $2 \mathrm{mM}$ glutamine, $100 \mu \mathrm{g} / \mathrm{ml}$ streptomycin, and $100 \mathrm{U} / \mathrm{ml}$ penicillin. Human adult adrenal glands were obtained at the time of nephrectomy performed for renal cell carcinoma. En block dissection of the primary neoplasm necessitated the excision of the adrenal gland. Tissue was not used if the patient had been treated with glucocorticoids or if the renal tumor was infiltrating the adrenal gland. The adrenal cortex was dissected free from the medulla, minced into $1-2-\mathrm{mm}$ pieces, and stirred for $1 \mathrm{~h}$ at $37^{\circ} \mathrm{C}$ in $20 \mathrm{ml}$ of Ham's F-12 complete media containing collagenase $(1 \mathrm{mg} / \mathrm{ml}) .2,000 \mathrm{U}$ of deoxyribonuclease were then added and the mixture was stirred for an additional $10 \mathrm{~min}$. The resultant cell suspension was filtered through a fine-mesh screen, washed once, and resuspended in media. Cells were counted using a standard hemocytometer and placed into culture plates $\left(2.0 \mathrm{~cm}^{2} /\right.$ well surface area; Costar, Cambridge, MA) at a density of $2.0 \times 10^{4}$ cells/well. Cell viability was $>85 \%$ in all experiments as determined by trypan blue exclusion. Cells were cultured at $37^{\circ} \mathrm{C}$ in a $5 \% \mathrm{CO}_{2}$ environment. The cells were incubated overnight before addition of the fatty acids.

\section{ACTH stimulation}

Linoleic, hexacosanoic, and lignoceric acids were dissolved in absolute ethanol to give $3 \mathrm{mg} / \mathrm{ml}$ stock solutions. Aliquots of the fatty acid solutions were diluted in media and added to triplicate wells containing adrenocortical cells to give final fatty acid concentrations of $5 \mu \mathrm{M}$. Control wells received the same volume of ethanol diluted in media. The addition of ethanol (final concentration $0.05 \%$ ) to the media did not affect cortisol release. After incubating for $24 \mathrm{~h}, 100 \mu \mathrm{l}$ aliquots of ACTH-(1-24) (Organon Pharmaceutical, West Orange, NJ) were added to provide a concentration range of $10^{-12}-10^{-6} \mathrm{M}$ in the adreno- 
cortical cell cultures. Basal production of cortisol after $48 \mathrm{~h}$ in culture was also measured for each of the fatty acids and control. The total volume in each well was $1 \mathrm{ml}$. Duplicate $50 \mu \mathrm{l}$ aliquots were removed from each well $24 \mathrm{~h}$ after ACTH addition and stored at $-20^{\circ} \mathrm{C}$ for cortisol measurement.

\section{Cortisol measurement}

RIA for cortisol was performed using $50 \mu \mathrm{l}$ of sample and $0.2 \mathrm{ml}$ of $0.1 \%$ gel PBS ( $\mathrm{pH} 7.0$ ). Cortisol standards were prepared to provide a range of 0.125-6 ng per 50 $\mu \mathrm{l} .200 \mu \mathrm{l}$ of a 1:500 dilution of cortisol antibody (cross-reactivities: 11-deoxycortisol $7.8 \%$, cortisone $1.6 \%$, all other adrenal steroids $<1 \%$, Western Research Chemical Corp., Ft. Collins, $\mathrm{CO}$ ) were added to all tubes except those used for calculation of nonspecific binding, which received an equal volume of normal rabbit serum previously diluted 1:500. All assay tubes were incubated for $60 \mathrm{~min}$ at room temperature, then at $4^{\circ} \mathrm{C}$ for an additional $30 \mathrm{~min}$. Subsequent procedures were performed at $4^{\circ} \mathrm{C} .100 \mu \mathrm{l}\left[{ }^{3} \mathrm{H}\right] \operatorname{cortisol}(15$, $000 \mathrm{cpm}$ ) were then added to each tube, vortexed, and then incubated in the ice-water bath for $90 \mathrm{~min}$ before adding $1 \mathrm{ml}$ cold $0.25 \%$ charcoal- $0.025 \%$ dextran in gel PBS. The tubes were vortexed, incubated for $20 \mathrm{~min}$, and centrifuged at $2,500 \mathrm{~g}$ for $20 \mathrm{~min}$. The supernatants were mixed with $10 \mathrm{ml}$ Ready-Solv scintillation cocktail (Beckman Instruments, Inc., Fullerton, CA) and counted. Cortisol concentrations were calculated from a standard curve using a four-parameter best-fit computer program. Intra- and interassay coefficients of variation were $<10 \%$ in all experiments.

\section{Membrane microviscosity measurements}

Human adrenocortical cells were cultured overnight in plastic Petri dishes (Falcon Labware, Oxnard, CA; $57 \mathrm{~cm}^{2}$ per dish surface area) at a density of $2 \times 10^{4}$ cells/ml (total volume $30 \mathrm{ml}$ ). Dilutions of linoleic acid, hexacosanoic acid, lignoceric acid, or ethanol were added to separate dishes to give final concentrations of $5 \mu \mathrm{M}$. Adrenocortical cells, scraped after $24 \mathrm{~h}$ of culture in the presence of the fatty acids, were centrifuged at $125 \mathrm{~g}$ for $10 \mathrm{~min}$, washed once, and resuspended in $0.5 \mathrm{ml}$ PBS ( $\mathrm{pH} 7.4$ ) with $0.15 \mathrm{mM}$ EDTA. The resulting cell suspensions were homogenized in $0.3 \mathrm{M}$ sucrose in a 1:10 dilution of PBS, containing $0.15 \mathrm{mM}$ EDTA, using a glass homogenizer. After centrifuging at $100 \mathrm{~g}$ for $10 \mathrm{~min}$, the supernatants were removed, centrifuged at $15,000 \mathrm{~g}$ for $20 \mathrm{~min}$, then at $100,000 \mathrm{~g}$ for $60 \mathrm{~min}$. The $100,000 \mathrm{~g}$ membrane pellets were homogenized and resuspended in PBS (pH 7.1). DPH was dissolved in THF at a concentration of $2 \mathrm{mM}$ before being dispersed in PBS, $\mathrm{pH} 7.1$, to provide a final concentration of 2 $\mu \mathrm{M}$. This was sparged with $\mathrm{N}_{2}$ gas for 20 min to remove traces of THF before use. The membrane suspensions were incubated with an equal volume of the PBS-DPH dispersion for $1 \mathrm{~h}$ at room temperature. Each membrane sample was subjected to polarization analysis at $37^{\circ} \mathrm{C}$ using a fluorescence spectrophotometer (MPF-66; Perkin-Elmer Corp., Norwalk, CT). Excitation wavelengths used were between 426 and 434 nM. Fluorescence polarization $(P)$ was calculated according to the equation: $P=\left(I_{V}-G \cdot I_{H}\right) /\left(I_{V}+G \cdot I_{H}\right)$, where $I_{V}$ and $I_{H}$ are the relative fluorescence intensities measured at an angle $90^{\circ}$ to the incident beam with the emission polarizer in the vertical and horizontal positions, respectively, and $G=I_{V} / I_{H}$ was measured with the excitation polarizer in the horizontal position (10). The intensities of the fluorescence by membranes incubated without DPH were subtracted from the corresponding values with DPH before the final calculation of fluorescence polarization.

\section{Statistical analysis}

Results are expressed as the mean $\pm \mathrm{SD}$. Statistical comparisons were made using the unpaired $t$ test.

\section{Results}

Adrenocortical cells incubated with $5 \mu \mathrm{M}$ hexacosanoic acid showed a decreased cortisol response to ACTH stimulation as compared with control cells. Dose-response studies demonstrated that the concentration of ACTH required for $50 \%$ maximal stimulation of cortisol release was tenfold higher for cells that had been cultured in the presence of hexacosanoic acid as compared with controls (Fig. 1). Basal production of cortisol was also significantly lower $(P<0.002)$ in the cells incubated with hexacosanoic acid (Table I). Cortisol release after stimulation with $10^{-7} \mathrm{M}$ ACTH was not significantly different, however, between control cells and those cultured in the presence of any of the fatty acids. Incubation of adrenocortical cells with lignoceric acid, a C24 saturated fatty acid, also resulted in a decreased basal (Table I) and ACTH-stimulated cortisol response (Fig. 1). Cortisol output from cells incubated with linoleic acid, a C18 unsaturated fatty acid, was not significantly different from control cultures (Fig. 1).

The polarization constants of cell membranes cultured with hexacosanoic and lignoceric acids were significantly higher $(P<0.002)$ than measurements from control cells and those incubated with linoleic acid (Fig. 2).

\section{Discussion}

A decrease in cell membrane microviscosity has been shown to result in increased receptor binding of a number of hormones, including prolactin (11-13), luteinizing hormone (LH) (14), and thyroid-stimulating hormone (15). Scatchard analyses of prolactin binding to hepatic cell membranes $(11,16)$ and $\mathrm{LH}$ binding to corpora lutea (14) show this to be due to an increase in number of hormone receptors. Conversely, an increase in hepatic or mammary cell membrane microviscosity resulted in a decrease in prolactin binding (17-19). Also, studies by Bash-

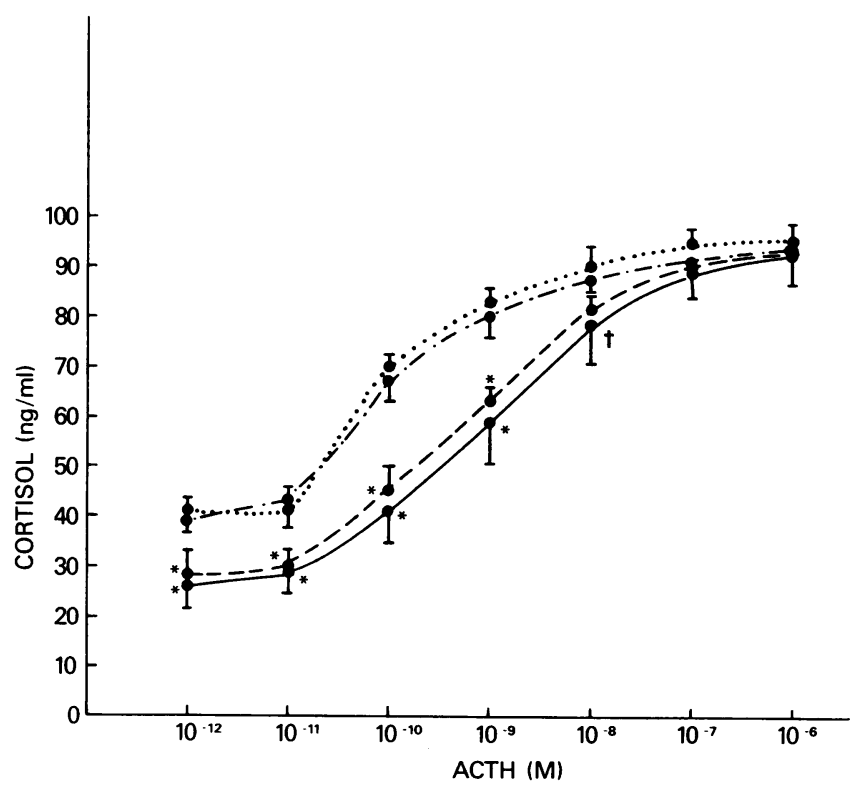

Figure 1. Cortisol response to stimulation with increasing concentrations of ACTH from adrenocortical cells cultured in the presence of the indicated fatty acids or $0.05 \%$ ethanol (control). Each point is the mean \pm SD of cortisol levels from six wells measured in duplicate. These data are representative of one of three experiments. Cortisol release after stimulation with $10^{-12}-10^{-9} \mathrm{M}$ ACTH was significantly lower $(P<0.002)$ from cells cultured in the presence of hexacosanoic acid $(---)$ or lignoceric acid $(-)$ than from control $(\cdots)$ or linoleic acid-treated $(-\cdot-)$ cells. $* P<0.002 ; \dagger P<0.05$. 
Table I. Basal Cortisol Release after 48 hrom Adrenocortical Cells Cultured in the Presence of Fatty Acids or $0.05 \%$ Ethanol (Control)

\begin{tabular}{ll}
\hline Fatty acid & Cortisol \\
\hline & $n g / m l$ \\
Control & $41 \pm 3.2$ \\
Linoleic & $39 \pm 4.6$ \\
Lignoceric & $26 \pm 2.9^{*}$ \\
Hexacosanoic & $28 \pm 4.2^{*}$ \\
\hline
\end{tabular}

${ }^{*} P<0.002$ compared with control and linoleic acid-treated cells.

ford et al. have demonstrated an increase in the binding of ACTH to human adrenal tissue after the membrane microviscosity is decreased via an elevation in temperature (15). This suggests that changes in membrane microviscosity may also modulate ACTH receptors.

After demonstrating that the membrane microviscosity of red blood cells obtained from individuals with ALD is greater than that of red blood cells from normal individuals, we proposed that the abnormal accumulation of LCFA in endocrine tissues could alter their response to trophic hormones (9). The present study was designed to address this hypothesis and demonstrates that adrenocortical cells that had been incubated with LCFA have an impaired response to ACTH stimulation. As expected, these cells also show an increase in fluorescence polarization, an index of membrane microviscosity $(20,21)$. Note that the concentration of hexacosanoic acid used in these experiments, $5 \mu \mathrm{M}$, is similar to the plasma concentration in individuals with ALD (5).

It appears that this effect is not limited to hexacosanoic acid since cells incubated with lignoceric acid, another LCFA that is elevated in patients with ALD, showed a similar increase in membrane microviscosity and decrease in basal and ACTH-stimulated cortisol release. This is consistent with the hypothesis that many LCFA, which have been shown to increase membrane microviscosity $(22,23)$, exert their effects by

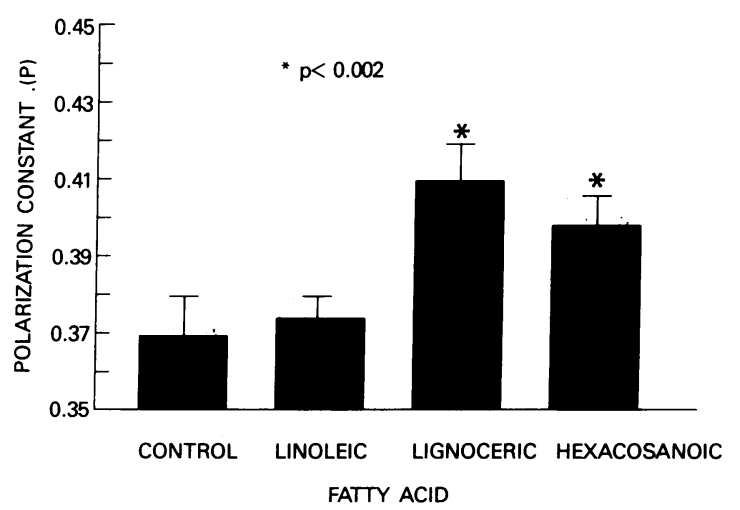

Figure 2. Polarization constants of adrenocortical cell membranes after $24 \mathrm{~h}$ of culture in presence of the indicated fatty acids or $0.05 \%$ ethanol (control). Each result is the mean \pm SD of four to six measurements from each of three samples in each group. The polarization constants of cells cultured in the presence of hexacosanoic or lignoceric acids were significantly higher $(P<0.002)$ than cells cultured with ethanol or linoleic acid. suppressing availability of hormonal receptors. Note the observation that this suppression can be overcome by exposing the LCFA-treated cells to high concentrations of ACTH. We propose that patients with ALD develop adrenal insufficiency due to an increase in adrenal cell membrane microviscosity, leading to a decreased ability to respond to ACTH. This decrease is trophic support may contribute to the histologic changes and atrophy seen in the adrenal glands of affected individuals. Additional evidence for an abnormality in ACTH receptor binding in patients with ALD has been provided by a recent report demonstrating that in contrast to mononuclear leukocytes from unaffected individuals, leukocytes from a patient with ALD have no detectable ACTH binding sites (24).

Therapeutic approaches to patients with ALD have included dietary restriction of LCFA (25), plasmapharesis (26), bone marrow transplantation (27), and administration of carnitine or clofibrate (28). None of these treatments have been completely effective in either decreasing plasma levels of LCFA or altering the clinical course of the disease. A recent report has shown that when skin fibroblasts obtained from patients with ALD are cultured in the presence of oleic acid, a medium-chain, unsaturated fatty acid, their synthesis of LCFA is decreased (29). Also, ALD patients treated with dietary oleic acid supplements showed decreases in plasma and erythrocyte levels of hexacosanoic acid $(30,31)$. One of these individuals also demonstrated objective improvement in nerve conduction studies.

In theory, this type of therapy may also decrease the membrane microviscosity of patients with ALD since incubating cell membranes with medium-chain, unsaturated fatty acids also decreases membrane microviscosity (23). Altering the membrane defects early in the disease, by decreasing membrane microviscosity and the synthesis of LCFA, may attenuate the pathologic changes affecting the nervous and endocrine systems of individuals with ALD. Further investigations with this type of intervention before the onset of symptoms are needed.

\section{References}

1. Menkes, J. H., and L. M. Corbo. 1977. Adrenoleukodystrophy: accumulation of cholesterol esters with very long chain fatty acids. Neurology. 27:928-932.

2. Askanas, V., J. McLaughlin, W. K. Engel, and B. T. Adornato. 1979. Abnormalities in cultured muscle and peripheral nerve of a patient with adrenomyeloneuropathy. $N$. Engl. J. Med. 301:588-590.

3. Igarshi, M., H. H. Schaumburg, J. Powers, Y. Kishimoto, E. Kolodny, and K. Suzuki. 1976. Fatty acid abnormality in adrenoleukodystrophy. J. Neurochem. 26:851-860.

4. Kelley, R. I., N. S. Datta, W. B. Dobyns, A. K. Hajra, A. B. Moser, M. J. Noetzel, E. H. Zackai, and H. W. Moser. 1986. Neonatal adrenoleukodystrophy: new cases, biochemical studies and differentiation from Zewelleger and related peroxisomal polydystrophy syndromes. Am. J. Med. Genet. 23:869-901.

5. Moser, H. W., A. E. Moser, I. Singh, and B. P. O'Neill. 1984. Adrenoleukodystrophy: survey of 303 cases: biochemistry, diagnosis, and therapy. Ann. Neurol. 16:628-641.

6. Griffin, J. W., E. Goren, H. Schaumburg, W. K. Engel, and D. L. Loriaux. 1977. Adrenomyeloneuropathy: a probable variant of adrenoleukodystrophy. Neurology. 27:1107-1113.

7. Singh, I., A. B. Moser, H. W. Moser, and Y. Kishimoto. 1984. Adrenoleukodystrophy: impaired oxidation of very long chain fatty acids in white blood cells, cultured skin fibroblasts and amniocytes. Pediatr. Res. 18:286-289. 
8. Goldfischer, S., J. Collins, I. Rapin, B. Coltoff-Schiller, C. Chang, M. Nigro, V. H. Black, N. B. Javitt, H. W. Moser, and P. B. Lazanov. 1985. Peroxisomal defects in neonatal-onset and X-linked adrenoleukodystrophy. Science (Wash. DC). 227:67-70.

9. Knazek, R. A., W. B. Rizzo, J. D. Schulman, and J. R. Dave. 1983. Membrane microviscosity is increased in the erythrocytes of patients with adrenoleukodystrophy and adrenomyeloneuropathy. $J$. Clin. Invest. 72:245-248.

10. Chen, R. E., H. Edelhock, and R. J. Steiner. 1969. Physical Principles and Techniques of Protein Chemistry. S. J. Leach, editor. Academic Press, New York. 171-240.

11. Dave, J. R., R. A. Knazek, and S. C. Liu. 1981. Arachidonic acid, bradykinin, and phospholipase $A_{2}$ modify both prolactin binding capacity and fluidity of mouse hepatic membranes. Biochem. Biophys. Res. Commun. 103:727-738.

12. Dave, J. R., and R. A. Knazek. 1980. Prostaglandin $I_{2}$ modifies both prolactin binding capacity and fluidity of mouse liver membranes. Proc. Natl. Acad. Sci. USA. 77:6597-6600.

13. Dave, J. R., and R. J. Witorsch. 1984. Modulation of prolactin binding sites in vitro by membrane fluidizers. II. Age-dependent effects on rat ventral prostatic membranes. Biochim. Biophys. Acta. 772:321-327.

14. Danforth, D. R., M. A. Wells, and R. L. Stouffer. 1985. Modulation of membrane fluidity in the primate (Macaca mulatta) corpus luteum: correlations with changes in gonadotropin binding. Endocrinology. 117:755-761.

15. Bashford, C. L., S. J. Harrison, G. K. Radda, and Q. Medhi. 1975. The relation between lipid mobility and the specific hormone binding of thyroid membranes. Biochem. J. 146:473-479.

16. Knazek, R. A., S. C. Liu, J. R. Dave, R. J. Christy, and K. A Keller. 1981. Indomethacin causes a simultaneous decrease of both prolactin binding and fluidity of mouse liver membranes. Prostaglandins Leukotrienes Med. 6:403-411.

17. Knazek, R. A., S. C. Liu, L. M. St. Amand, J. R. Dave, and R. J. Christy. 1981. Cholesterol accentuates the effect of unsaturated fatty acid deficiency on mammary gland development. Proc. Am. Assoc. Cancer Res. 22:28. (Abstr.)

18. Knazek, R. A., and S. C. Liu. 1979. Dietary essential fatty acids are required for maintenance and induction of prolactin receptors. Proc. Soc. Exp. Biol. Med. 162:346-350.

19. Knazek, R. A., and S. C. Liu. 1981. Effects of dietary essential fatty acids on murine mammary gland development. Cancer Res. 41:3750-3751.
20. Shinitzky, M., and M. Inbar. 1976. Microviscosity parameters and protein mobility in biological membranes. Biochim. Biophys. Acta. 433:133-149.

21. Shinitzky, M., and Y. Barenholz. 1978. Fluidity parameters of lipid regions determined by fluorescence polarization. Biochim. Biophys. Acta. 515:367-394.

22. Lentz, R. B., Y. Barenholz, and T. E. Thompson. 1976. Fluorescence depolarization studies of phase transitions and fluidity in phospholipid bilayer. Biochemistry. 15:4521-4537.

23. Orly, J., and M. Schram. 1975. Fatty acids as modulators of membrane functions: catecholamine-activated adenylate cyclase of the turkey erythrocyte. Proc. Natl. Acad. Sci. USA. 72:3433-3437.

24. Meyer, W. J., E. M. Smith, G. E. Richards, N. G. Greger, P. G. Brosnan, and B. S. Keenan. 1987. ACTH receptor defect in adrenoleukodystrophy (ALD). Pediatr. Res. 21:465A. (Abstr.)

25. Van Duyn, M. A., A. E. Moser, F. R. Brown, N. Sacktor, A. Liu, and H. W. Moser. 1984. The design of a diet restricted in saturated very long-chain fatty acids: therapeutic application in adrenoleukodystrophy. Am. J. Clin. Nutr. 40:277-284.

26. Murphy, J. V., K. M. Marquardt, H. W. Moser, and M. A. Van Duyn. 1982. Treatment of adrenoleukodystrophy by diet and plasmapharesis. Ann. Neurol. 12:220a. (Abstr.)

27. Moser, H. W., F. R. Brown, P. J. Tutschka, A. M. Yeager, I. Singh, and G. W. Santos. 1983. Bone marrow transplantation in adrenoleukodystrophy. Neurology. 32:254A. (Abstr.)

28. Brown, F. R., M. A. Van Duyn, A. B. Moser, J. D. Schulman, W. B. Rizzo, R. D. Snyder, J. V. Murphy, S. Kamoshita, C. J. Migeon, and H. W. Moser. 1982. Adrenoleukodystrophy: effects of dietary restriction of very long chain fatty acids and of administration of carnitine and clofibrate on clinical status and plasma fatty acids. Johns Hopkins Med. J. 151:164-172.

29. Rizzo, W. B., P. A. Watkins, M. W. Phillips, D. Cranin, B. Campbell, and J. Avigan. 1986. Adrenoleukodystrophy: oleic acid lowers fibroblast saturated C22-26 fatty acids. Neurology. 36:357-361.

30. Rizzo, W. B., M. W. Phillips, A. L. Dammann, R. T. Leshner, S. S. Jennings, J. Avigan, and V. K. Proud. 1987. Adrenoleukodystrophy: dietary oleic acid lowers hexacosanoate levels. Ann. Neurol. 21:232-239.

31. Moser, A. B., J. Borel, A. Odone, S. Naidu, D. Cornblath, D. B. Sanders, and H. W. Moser. 1987. A new dietary therapy for adrenoleukodystrophy: biochemical and preliminary clinical results in 36 patients. Ann. Neurol. 21:240-249. 